\title{
Glandular fever-like illness associated with sulphasalazine
}

\author{
DAVID L. CARR-LOCKE \\ M.A., M.B., B.Chir., M.R.C.P.
}

MUNTAZ ALI

M.B., M.R.C.P.

Leicester General Hospital, Leicester LE2 7LX

\section{Summary}

A patient with ulcerative colitis is described in whom a glandular fever-like illness was associated with the use of sulphasalazine which recurred in part on reexposure to the drug. This complication has been previously described three times from the United States but not from the United Kingdom.

\section{Introduction}

Sulphasalazine (Salazopyrin) is widely prescribed for the treatment of inflammatory bowel disease. Minor side effects such as nausea are common but potentially serious side effects are rarely encountered. We wish to describe a case with a glandular fever-like illness with fever, rash, mouth ulcers, lymphadenopathy and lymphocytosis associated with sulphasalazine therapy.

\section{Case report}

A diagnosis of ulcerative colitis was made in a 30year-old Caucasian male and treatment with sulphasalazine $3 \mathrm{~g}$ daily in divided doses was started. He was on no other drug treatment. Three weeks later he developed fever, mouth ulceration and a generalized skin rash.

Sulphasalazine was stopped and he was referred to hospital. On admission he appeared ill, had a pyrexia of $40^{\circ} \mathrm{C}$, multiple large oropharyngeal ulcers, a generalized maculopapular rash with petechiae on the legs, and multiple lymph nodes were palpable in the neck, axillae and inguinal regions. The liver was just palpable but not tender, there were no genital lesions and his chest was clear. His colitis was in remission.

Investigations showed a haemoglobin of $15.4 \mathrm{~g} / \mathrm{dl}$, a white cell count of $24 \times 10^{9} /$ litre, with a differential of $41 \%$ neutrophil leucocytes, $2 \%$ eosinophils, $5 \%$ monocytes and $52 \%$ lymphocytes of which $34 \%$ were atypical. Liver function tests showed a raised gamma

Correspondence: Dr D. L. Carr-Locke, Department of Medicine, Clinical Sciences Building, Leicester Royal Infirmary, PO Box 65, Leicester LE2 7LX. glutamyl transferase of 61 iu./litre (normal $<50$ iu./litre) but normal alanine transaminase, alkaline phosphatase and bilirubin. A Monospot (Brocades) test for infectious mononucleosis was negative and paired sera showed no rise in the titre of cytomegalovirus or toxoplasma antibodies. Titres against Epstein-Barr virus measured on stored sera later proved to be within the reference range. Other biochemical and haematological investigations were normal including immunoglobulins. Chest $\mathrm{X}$-ray was also normal. With supportive measures he made a complete recovery within 2 weeks of stopping the sulphasalazine when his blood count also returned to normal. Six weeks later his colitis relapsed and a single oral dose of $500 \mathrm{mg}$ sulphasalazine was given. Twenty-four hours later he developed a pyrexia and skin rash identical to his previous eruption, but no other symptoms. Further treatment with sulphasalazine was not considered justified and his colitis remained satisfactorily controlled by steroid enema alone.

\section{Discussion}

We feel that there is strong circumstantial evidence to implicate sulphasalazine in our patient's glandular fever-like illness. Three other cases with similar features to ours have been described in association with sulphasalazine treatment, all from the United States. Sotolongo et al. (1978) reported a case of a 19 year-old female who presented with fever, skin rash, lymphadenopathy, leucocytosis and eosinophilia one month after sulphasalazine was begun for inflammatory bowel disease. Her renal and hepatic function deteriorated to the point of encephalopathy but she subsequently recovered. Chester, Diamond and Schreiner (1978) described an acute allergic reaction characterized by fever, rash, eosinophilia and hepatitis. This resolved when the drug was discontinued, 3 weeks after the initiation of therapy. Mihas, Goldenberg and Slaughter (1978) reported the development of fever, skin rash, arthralgia, lymphocytosis, lymphadenopathy and hepatitis coincident with administration of sulphasalazine. All these cases had severe hepatic involvement which was not present in our 
case. The illness in our patient was initially confused with infectious mononucleosis on the basis of clinical features and atypical lymphocytosis. It is therefore important to be aware of a possible drug reaction to sulphasalazine as an alternative cause for a glandular fever-like illness.

\section{Acknowledgment}

We are grateful to Dr C. P. Alexander for permission to report this case.

\section{References}

Chester, A.C., Diamond, L.H. \& SChreiner, G.E. (1978) Hypersensitivity to salicylazosulfapyridine. Archives of Internal Medicine, 1138, 138.

Mihas, A.A., Goldenberg, D.J. \& Slaughter, R.L. (1978) Sulfasalazine toxic reactions. Hepatitis, fever and skin rash with hypocomplementemia and immune complexes. Journal of American Medical Association, 239, 2590.

Sotolongo, R.P., NeEFE, L.I., RUdZKI, C. \& IsCHAK, K.G. (1978) Hypersensitivity reaction to sulfasalazine with severe hepatotoxicity. Gastroenterology, 75, 95. 